\title{
Dietary sugars and micronutrient dilution in normal adults aged 65 years and over
}

\author{
Sigrid Gibson * \\ SiG-Nurture Nutrition Consultancy, 11 Woodway, Guildford, Surrey, GU1 2TF, UK
}

Submitted 16 January 2001: Accepted 26 March 2001

\begin{abstract}
Objective: To examine the relationship between non-milk extrinsic sugars (NMES) concentration and micronutrient intakes and status in free-living older people.

Design: The National Diet and Nutrition Survey of people aged 65 years and over; a cross-sectional study in Britain in 1994/5.

Subjects and methods: Eight hundred and six men and women living in private households who were not on medication for nutritional disorders. Subjects were classified into four groups (Q1 to Q4), using cut-off points corresponding to quartiles of energy from NMES. Relationships were examined between dietary NMES concentration and intakes of calcium, iron, riboflavin, folate, vitamin $\mathrm{C}$ and vitamin D. Status indices were also assessed in each group.

Results: Overall, a small proportion of men and women had intakes below the Lower Reference Nutrient Intake (LRNI) for calcium, iron, folate, riboflavin or vitamin C, while vitamin D intakes were universally low. Intakes of micronutrients tended to be highest at moderate levels of NMES in the diet (Q2 and Q3, equivalent to 8-15\% of energy from NMES). Micronutrient status was low for riboflavin in 38\% of the sample, while $15 \%$ had low vitamin C status and more than 10\% were anaemic. There was little evidence that poorer nutrient status was associated with higher levels of dietary NMES. Although some indices of folate status were lower in Q4, this is most likely to reflect confounding by smoking. Energy intake accounted for $20-40 \%$ of the variance in micronutrient intakes, compared with less than 5\% for NMES concentration.

Conclusions: A diet moderately high in NMES (up to around 15\% of energy) is unlikely to have a detrimental impact on micronutrient intake or status in this age group. Energy intake is the major determinant of micronutrient adequacy.
\end{abstract}

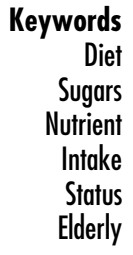

People over the age of 65 in Britain today can look forward to more years of healthy retirement than previous generations. This has come about chiefly as a result of improved public health and nutrition over the last century and better medical treatment in the past 40 years. Nonetheless, there is a still a minority for whom nutrient intakes may be inadequate and nutritional status suboptimal.

Older people are potentially 'at risk' of low micronutrient intakes and status because energy requirements decline with age, while most micronutrient requirements do not ${ }^{1}$. The latter may even increase if absorption is less efficient or adversely affected by disease or medication. Dietary quality becomes more important at lower energy intakes.

The UK Department of Health's report ${ }^{2}$, The Nutrition of Elderly People, recommended that elderly people should consume "a diet containing nutrient-dense foods". It also asserts that "a reduction in sugar intakes is especially important, given the probability of higher than average consumption by elderly people". The report also warns, "if large amounts of foods rich in simple sugars are consumed, appetite for a more varied and nutrient rich diet may be blunted".

The aim of this project was to examine whether diets high in sugars are observed to compromise micronutrient intakes and/or micronutrient status in older adults. Nonmilk extrinsic sugars (NMES), rather than total sugars, were used as the basis of the analysis, on the grounds that UK dietary guidelines currently use this definition ${ }^{1,3}$. The term NMES is similar, but not identical, to the concept of 'added sugars'; it comprises all sugars, whether refined or unprocessed, that are not part of the cellular structure of foods. Sugars in fruit juices and 50\% of the sugars in cooked and processed fruit are classified as NMES, while milk sugars are specifically excluded. NMES constituted 
approximately $60 \%$ of the intake of total sugars among free-living men and women in The National Diet and Nutrition Survey of people aged 65 years and over $(\mathrm{NDNS} 65+)^{4}$.

The NDNS65+ was chosen for further analysis because it provides recent dietary and biochemical data of the highest quality on a national sample of older adults living in Britain. The official report identified a small proportion of the free-living older population who had low values of certain vitamin status indices: notably vitamin C, vitamin $\mathrm{D}$, riboflavin and folate ${ }^{4}$. These, together with the minerals calcium and iron, were chosen for the present investigation because concerns have been raised over their adequacy in diets, and because indices for the deficiencies they represent are fairly well established.

Several studies have examined the concept of nutrient dilution with diets high in sugars. Comparison is hampered by differences in the definitions used for sugars and in the outcomes studied, which include nutrient intake, nutrient density, and more arbitrary indicators of diet quality. One recent study from the United States claimed to find a relationship between high sugar intakes and a poorer score in the healthy eating index, but did not evaluate nutrient intakes ${ }^{5}$. The smaller studies have sometimes lacked the statistical power to demonstrate significant associations ${ }^{6}$. A few studies have evaluated micronutrient intakes against reference values, and examined trends across the range of dietary sugars intake $e^{3,7-13}$. Most have found little evidence of an inverse relationship between micronutrient intakes and sugar intakes in the normal range. Even in a population with high average intakes of NMES (pre-school children, mean $18 \%$ NMES), where there was some evidence of micronutrient dilution at the highest levels of sugar intake, micronutrient intakes were mostly adequate. The exceptions (iron, zinc and vitamin D) were low irrespective of sugars intake ${ }^{10}$.

The present study has examined biochemical indices of status in addition to dietary intakes, which are more vulnerable to measurement error and under-reporting. Biochemical assessments, although subject to errors and influences such as illness and medication, can provide a perspective on longer-term nutritional status.

\section{Methods}

The methodology of the National Diet and Nutrition Survey of people aged 65 years and over has been explained in detail in the published report ${ }^{4}$. The survey included both free-living people and those living in institutions, but the present analysis was confined to the free-living sample as representative of the normal healthy population of this age group.

About two-thirds of the individuals contacted provided a 4-day weighed dietary record $(n=1275)$ and around two-thirds of these provided a blood sample for analysis.
Records were selected for analysis in this project if analytical results were available for key nutrients (ferritin, vitamin C, vitamin D: $n=847$ ), and respondents were not taking medication prescribed for nutrition or blood disorders such as anaemia $(n=41)$. Dietary supplement use was not considered grounds for exclusion. The final sample comprised 806 respondents (429 men, 377 women).

Data analysis was carried out using SPSS software (SPSS, UK). The percentage of dietary energy obtained from NMES was calculated for every individual from the nutritional database. Using sex-specific quartiles of the distribution, respondents were classified into four equal groups, from Q1 to Q4 corresponding to increasing proportions of NMES in the diet. Energy and nutrient intakes were compared between same-sex groups. Nonparametric tests were used to compare differences across all groups (Kruskal-Wallis), and between lowest and highest quartiles of NMES (Mann-Whitney test). Chisquare tests were used for evaluating differences between groups with regard to the categorical variables. Relationships between NMES and micronutrient intakes were also investigated using regression.
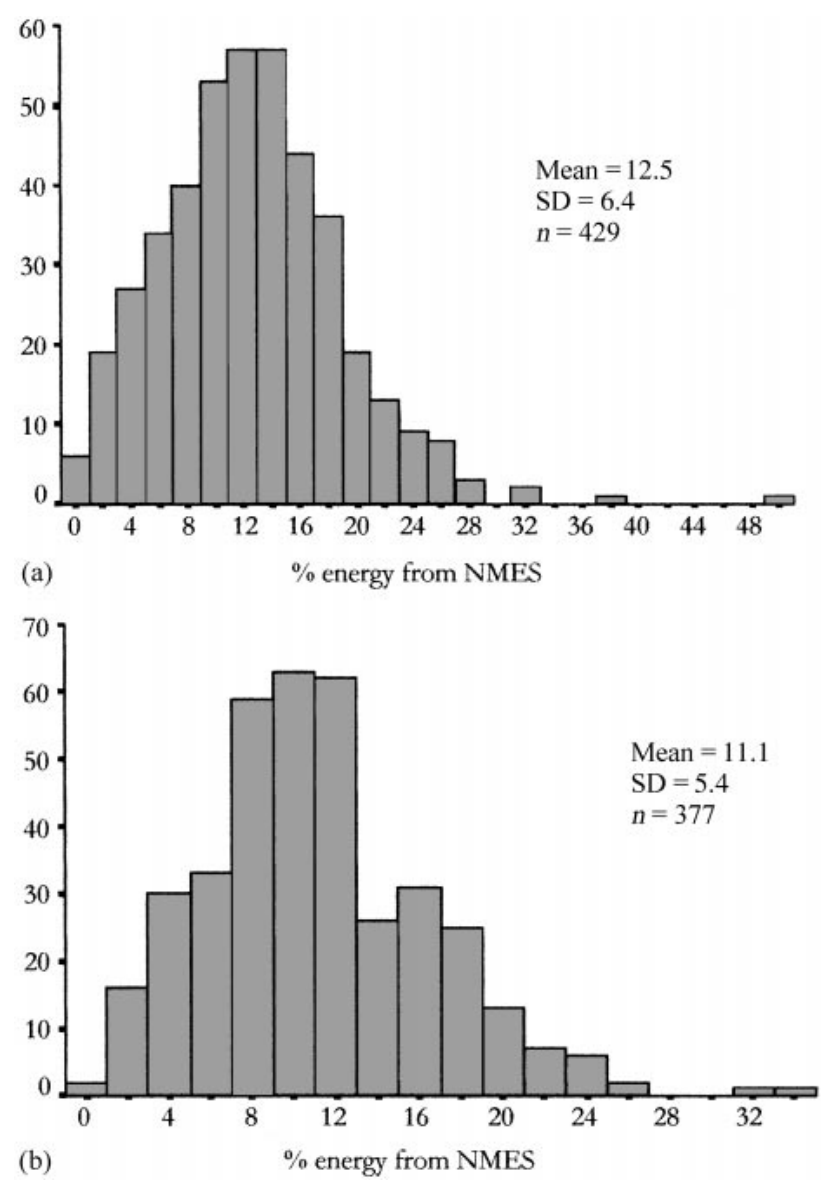

Fig. 1 Intake of NMES as a percentage of dietary energy for (a) men and (b) women. SD = standard deviation 


\section{Results}

Intake of NMES as a percentage of dietary energy The distribution of NMES intakes is illustrated for men and women in Fig. 1. On average, men had slightly higher intakes than women (12\% vs. 11\% energy from NMES) while mean NMES intakes in the respective quartiles ranged from $5 \%$ of energy for the lowest NMES groups (Q1), up to 21\% (men) or 18\% (women) for the highest NMES groups (Q4). The 50\% of respondents in Q2 and Q3 had intakes of NMES in the range $8-16 \%$ of energy (men) and $8-14 \%$ of energy (women) (Table 1).

\section{Background variables}

As shown in Table 1, men and women consuming diets low in NMES (Q1, or lowest 25\% of the distribution) were slightly younger than those in Q4. The age difference between the quartiles was just statistically significant for men $(P=0.048)$ but not for women $(P=0.057)$. Body mass index (BMI) among men decreased with increasing (percentage) NMES intake from Q1 to Q4 $(P=0.017)$ and the age-adjusted correlation was also significant $(r=$ $-0.16, P=0.001)$. Women in $\mathrm{Q} 4$ had a mean BMI that was one percentage point lower than those in Q1, but neither this nor the age-adjusted correlation reached conventional significance $(P=0.058)$. There were no significant differences between NMES groups in education, receipt of benefits or smoking habit, or in the proportion living alone.

More than two-thirds of respondents reported some form of long-standing illness or disability (e.g. heart disease, hypertension, arthritis and diabetes), but the proportion did not vary significantly between NMES groups. Severity of condition was not assessed ${ }^{4}$. A small percentage of respondents in the analysis ( $5 \%$ of men, $11 \%$ of women) stated that their eating had been affected by illness during the week of the dietary survey, but again a similar proportion in each group was affected. As noted in the official report of this survey ${ }^{4}$, a fairly high

Table 1 Background characteristics of adults, according to level of dietary NMES

\begin{tabular}{|c|c|c|c|c|c|c|c|}
\hline \multirow[b]{3}{*}{ MEN } & \multirow[b]{3}{*}{$n$} & \multicolumn{4}{|c|}{ NMES quartile } & \multirow[b]{2}{*}{ Total } & \multirow[b]{3}{*}{$P$-value } \\
\hline & & 1 & 2 & 3 & 4 & & \\
\hline & & 107 & 107 & 108 & 107 & 429 & \\
\hline Age (years) & $\begin{array}{l}\text { Mean } \\
\text { SE }\end{array}$ & $\begin{array}{l}74.0 \\
0.6\end{array}$ & $\begin{array}{l}75.6 \\
0.7\end{array}$ & $\begin{array}{l}75.6 \\
0.6\end{array}$ & $\begin{array}{l}76.6 \\
0.7\end{array}$ & $\begin{array}{l}75.5 \\
0.3\end{array}$ & 0.048 \\
\hline Energy intake (kJ) & $\begin{array}{l}\text { Mean } \\
\text { SE }\end{array}$ & $\begin{array}{l}7405 \\
183\end{array}$ & $\begin{array}{l}7968 \\
191\end{array}$ & $\begin{array}{l}8278 \\
177\end{array}$ & $\begin{array}{l}8096 \\
187\end{array}$ & $\begin{array}{l}7938 \\
93\end{array}$ & 0.002 \\
\hline$\%$ energy from NMES & $\begin{array}{l}\text { Mean } \\
\text { Range }\end{array}$ & $\begin{array}{l}4.9 \\
1-8\end{array}$ & $\begin{array}{l}10.3 \\
8-12\end{array}$ & $\begin{array}{l}14.1 \\
12-16\end{array}$ & $\begin{array}{l}20.7 \\
16-49\end{array}$ & 12.5 & 0.0001 \\
\hline Body mass index $\left(\mathrm{kg} \mathrm{m}^{-2}\right)$ & $\begin{array}{l}\text { Mean } \\
\text { SE }\end{array}$ & $\begin{array}{l}26.8 \\
0.4\end{array}$ & $\begin{array}{l}26.6 \\
0.3\end{array}$ & $\begin{array}{l}26.0 \\
0.3\end{array}$ & $\begin{array}{l}25.5 \\
0.3\end{array}$ & $\begin{array}{l}26.2 \\
0.2\end{array}$ & 0.017 \\
\hline Current smokers & $(\%)$ & 13 & 16 & 12 & 21 & 16 & NS \\
\hline Living alone & $(\%)$ & 22 & 22 & 28 & 26 & 24 & NS \\
\hline No academic qualifications & $(\%)$ & 46 & 56 & 47 & 51 & 50 & NS \\
\hline On benefits & (\%) & 34 & 34 & 33 & 41 & 36 & NS \\
\hline Chronic illness or disability & $(\%)$ & 74 & 68 & 71 & 69 & 71 & NS \\
\hline Illness affecting eating in survey week & (\%) & 7 & 6 & 4 & 6 & 5 & NS \\
\hline \multirow[t]{3}{*}{ Energy intake below $1.1 \times$ BMR } & $(\%)$ & 29 & 19 & 13 & 16 & 19 & 0.008 \\
\hline & & \multicolumn{4}{|c|}{ NMES quartile } & & \\
\hline & & 1 & 2 & 3 & 4 & Total & \\
\hline \multirow{2}{*}{$\frac{W O M E N}{\text { Age (years) }}$} & $n$ & 94 & 94 & 95 & 94 & 377 & $P$-value \\
\hline & $\begin{array}{l}\text { Mean } \\
\text { SE }\end{array}$ & $\begin{array}{l}75.1 \\
0.7\end{array}$ & $\begin{array}{l}77.1 \\
0.8\end{array}$ & $\begin{array}{l}76.5 \\
0.8\end{array}$ & $\begin{array}{l}78.3 \\
0.8\end{array}$ & $\begin{array}{l}76.7 \\
0.4\end{array}$ & NS $(0.057)$ \\
\hline Energy intake (kJ) & $\begin{array}{l}\text { Mean } \\
\text { SE }\end{array}$ & $\begin{array}{l}5420 \\
132\end{array}$ & $\begin{array}{l}5951 \\
141\end{array}$ & $\begin{array}{l}6352 \\
132\end{array}$ & $\begin{array}{l}6302 \\
148\end{array}$ & $\begin{array}{l}6007 \\
72\end{array}$ & 0.0001 \\
\hline \% energy from NMES & $\begin{array}{l}\text { Mean } \\
\text { Range }\end{array}$ & $\begin{array}{l}4.8 \\
1-8\end{array}$ & $\begin{array}{l}9.1 \\
8-11\end{array}$ & $\begin{array}{l}12.2 \\
11-14\end{array}$ & $\begin{array}{l}18.4 \\
14-34\end{array}$ & 11.1 & 0.0001 \\
\hline Body mass index $\left(\mathrm{kg} \mathrm{m}^{-2}\right)$ & Mean & $\begin{array}{l}1-8 \\
26.8 \\
0.5\end{array}$ & $\begin{array}{l}8-11 \\
27.3 \\
0.5\end{array}$ & $\begin{array}{l}11-14 \\
26.1 \\
0.4\end{array}$ & $\begin{array}{l}14-34 \\
25.8 \\
0.5\end{array}$ & $\begin{array}{l}26.5 \\
0.2\end{array}$ & NS \\
\hline Current smokers & $(\%)$ & 19 & 15 & 8 & 11 & 13 & NS \\
\hline Living alone & (\%) & 57 & 66 & 61 & 61 & 61 & NS \\
\hline No academic qualifications & (\%) & 76 & 69 & 68 & 73 & 72 & NS \\
\hline On benefits & $(\%)$ & 51 & 59 & 40 & 54 & 51 & NS \\
\hline Chronic illness or disability & (\%) & 71 & 69 & 66 & 68 & 69 & NS \\
\hline Illness affecting eating in survey week & (\%) & 11 & 15 & 8 & 11 & 11 & NS \\
\hline Energy intake below $1.1 \times$ BMR & (\%) & 46 & 30 & 17 & 21 & 28 & $<0.0001$ \\
\hline
\end{tabular}

$\mathrm{SE}=$ standard error; $\mathrm{NS}=$ not significant; $\mathrm{BMR}=$ basal metabolic rate. 
Table 2 Energy and nutrient intakes of adults over 65 years, according to level of NMES in the diet

\begin{tabular}{|c|c|c|c|c|c|c|c|c|}
\hline \multirow[b]{3}{*}{ MEN } & \multirow[b]{3}{*}{$n$} & \multicolumn{4}{|c|}{ NMES quartile } & \multirow{3}{*}{$\frac{\text { Total }}{429}$} & \multirow[b]{3}{*}{ KW $P$-value } & \multirow{3}{*}{$\begin{array}{l}\text { MW } P \text {-value } \\
\text { (Q1 vs. Q4) }\end{array}$} \\
\hline & & 1 & 2 & 3 & 4 & & & \\
\hline & & 107 & 107 & 108 & 107 & & & \\
\hline \multirow[t]{2}{*}{ Energy (kJ) } & Mean & 7405 & 7968 & 8278 & 8096 & 7938 & 0.002 & 0.005 \\
\hline & SE & 183 & 191 & 177 & 187 & 93 & & \\
\hline \multirow{2}{*}{$\mathrm{Ca}(\mathrm{mg})$} & Mean & 844 & 859 & 869 & 784 & 839 & NS & NS \\
\hline & SE & 33 & 27 & 27 & 26 & 14 & & \\
\hline \multirow{2}{*}{$\mathrm{Fe}(\mathrm{mg})$} & Mean & 11.5 & 11.1 & 11.4 & 10.6 & 11.1 & NS & NS $(0.053)$ \\
\hline & SE & 0.4 & 0.3 & 0.4 & 0.4 & 0.2 & & \\
\hline \multirow[t]{2}{*}{ Riboflavin (mg) } & Mean & 1.8 & 1.7 & 1.8 & 1.8 & 1.8 & NS & NS \\
\hline & SE & 0.1 & 0.1 & 0.1 & 0.1 & 0.0 & & \\
\hline \multirow[t]{2}{*}{ Folate $(\mu \mathrm{g})$} & Mean & 269 & 262 & 272 & 252 & 264 & NS & NS \\
\hline & SE & 8 & 9 & 10 & 8 & 4 & & \\
\hline \multirow[t]{2}{*}{ Vitamin C (mg) } & Mean & 69 & 67 & 68 & 58 & 65 & NS & 0.038 \\
\hline & SE & 4 & 4 & 4 & 4 & 2 & & \\
\hline \multirow[t]{2}{*}{ Vitamin D ( $\mu \mathrm{g})$} & Mean & 4.2 & 3.8 & 4.0 & 3.9 & 4.0 & NS & NS \\
\hline & SE & 0.4 & 0.2 & 0.3 & 0.3 & 0.1 & & \\
\hline \multicolumn{9}{|c|}{ NMES quartile } \\
\hline \multirow[b]{2}{*}{ WOMEN } & & 1 & 2 & 3 & 4 & Total & & MW $P$ \\
\hline & $n$ & 94 & 94 & 95 & 94 & 377 & $\mathrm{KW} P$-value & (Q1 vs. Q4) \\
\hline \multirow[t]{2}{*}{ Energy (kJ) } & Mean & 5420 & 5951 & 6352 & 6302 & 6007 & 0.0001 & 0.0001 \\
\hline & SE & 132 & 141 & 132 & 148 & 72 & & \\
\hline \multirow{2}{*}{$\mathrm{Ca}(\mathrm{mg})$} & Mean & 620 & 698 & 760 & 692 & 693 & 0.0001 & 0.039 \\
\hline & SE & 22 & 27 & 24 & 25 & 13 & & \\
\hline \multirow[t]{2}{*}{$\mathrm{Fe}(\mathrm{mg})$} & Mean & 8.2 & 9.2 & 9.3 & 8.5 & 8.8 & 0.006 & NS \\
\hline & SE & 0.3 & 0.3 & 0.3 & 0.3 & 0.2 & & \\
\hline \multirow[t]{2}{*}{ Riboflavin (mg) } & Mean & 1.2 & 1.6 & 1.6 & 1.4 & 1.4 & 0.0001 & NS \\
\hline & SE & 0.0 & 0.1 & 0.1 & 0.1 & 0.0 & & \\
\hline \multirow[t]{2}{*}{ Folate $(\mu \mathrm{g})$} & Mean & 197 & 225 & 218 & 205 & 211 & NS (0.06) & NS \\
\hline & SE & 7 & 9 & 7 & 8 & 4 & & \\
\hline \multirow[t]{2}{*}{ Vitamin C (mg) } & Mean & 51 & 65 & 65 & 65 & 61 & 0.04 & NS \\
\hline & SE & 3 & 5 & 4 & 5 & 2 & & \\
\hline \multirow[t]{2}{*}{ Vitamin D $(\mu \mathrm{g})$} & Mean & 2.8 & 2.8 & 2.8 & 2.6 & 2.8 & NS & NS \\
\hline & SE & 0.3 & 0.2 & 0.2 & 0.2 & 0.1 & & \\
\hline
\end{tabular}

$\mathrm{KW}=$ Krusal-Wallis; MW $=$ Mann-Whitney; $\mathrm{SE}=$ standard error; NS $=$ not significant.

proportion (19\% of men and $28 \%$ of women) had estimates of dietary energy intake that were implausible (less than 1.1 times basal metabolic rate) using the criterion of Goldberg ${ }^{14}$. Not surprisingly, the prevalence of suspected low energy reporters was highest in Q1, suggesting that some of the low nutrient intakes reported may be underestimates. The effect of excluding low energy reporters was examined but this reduced the power to demonstrate significant associations and did not materially affect the conclusions drawn. The results are therefore presented for the sample eligible according to the criteria specified in the Method section $(n=806)$.

\section{Dietary intakes}

Table 2 shows the means and standard errors for energy and micronutrient intakes by NMES group, while Fig. 2 illustrates means and 95\% confidence intervals together with the Estimated Average Requirement (EAR) or Reference Nutrient Intake (RNI) for comparison ${ }^{1}$. Energy intakes were lowest in Q1 and rose in a non-linear fashion with increasing consumption of sugars, peaking in Q3 $(P<0.0001)$. Adults in $\mathrm{Q} 4$ had higher total energy intakes than those in $\mathrm{Q} 1(P=0.005$ for men, $P<0.0001$ for women).

Among women in particular, nutrient intakes tended to show a quadratic or shallow bell-shaped association with NMES (Fig. 2). Calcium intakes in women were lowest in Q1 $(P=0.039)$. Iron intakes peaked in Q2 and Q3 but there was no difference between Q4 and Q1. Among men, iron and vitamin $\mathrm{C}$ intakes tended to be lower in Q4 than Q1 although this difference was not statistically significant for iron $(P=0.053)$. Intakes of other vitamins (riboflavin, folate and vitamin D) were not significantly different between lowest and highest NMES groups, in either sex.

The nature of the relationship between dietary NMES and micronutrient intakes was explored further by fitting regression curves and computing the percentage of variance explained by: (1) percentage NMES in the diet, and (2) energy intake. The results are given in Table 3. Among men, the only significant relationships observed 

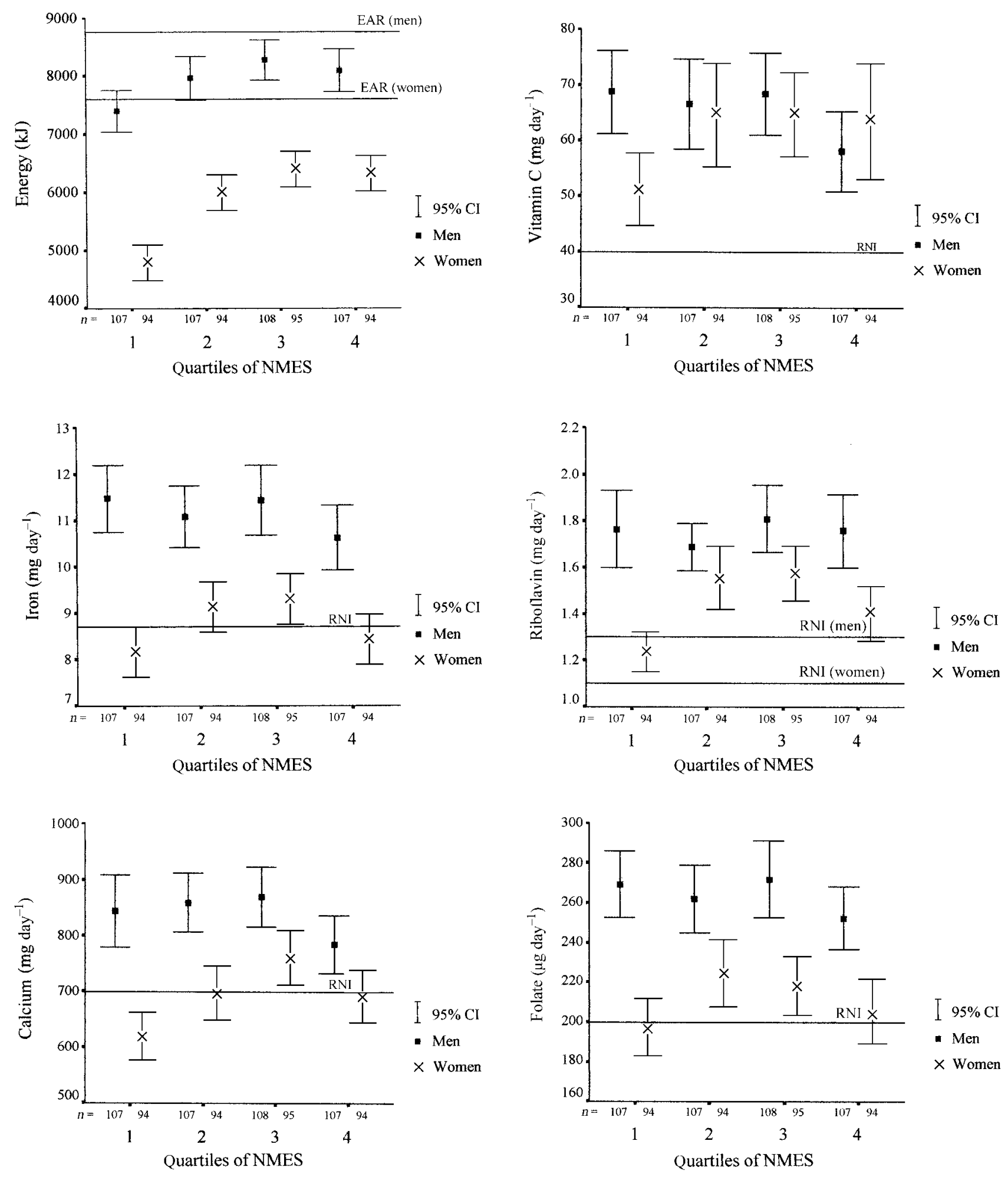

Fig. 2 Energy and micronutrient intakes by men and women according to level of dietary NMES, compared with RNI (or EAR in the case of energy). $95 \% \mathrm{Cl}=95 \%$ confidence interval

with NMES were for calcium and vitamin C, but in each case NMES explained only $2 \%$ of the variance. Among women, the quadratic curve produced the best fit and explained between $3 \%$ and $5 \%$ of the variance for iron, calcium, riboflavin and folate. By comparison, energy was a much more significant determinant of micronutrient intake, the simple linear regression explaining between $20 \%$ and $40 \%$ of the variance in iron, calcium, riboflavin and folate. 
Table 3 Percentage of the variance in micronutrient intakes explained by dietary NMES concentration, or energy intake (kJ)

\begin{tabular}{lccccr}
\hline & \multicolumn{2}{c}{ Men } & & \multicolumn{2}{c}{ Women } \\
\cline { 2 - 3 } \cline { 5 - 6 } & NMES* $^{*}$ & $\mathrm{~kJ}$ & & NMES $^{*}$ & $\mathrm{~kJ}$ \\
\hline Iron & 0 & 36 & & 28 \\
Calcium & 2 & 41 & & 32 \\
Riboflavin & 0 & 19 & & 19 \\
Folate & 0 & 30 & 3 & 20 \\
Vitamin C & 2 & 11 & & 0 & 6 \\
Vitamin D & 0 & 9 & 0 & 3 \\
\hline
\end{tabular}

* Quadratic curve.

\section{Evaluation of intakes relative to the Lower Reference Nutrient Intake (LRNI)}

The LRNI defines a level at which individuals are unlikely to be consuming adequate amounts of that nutrient to meet their requirements ${ }^{1}$. LRNIs can be used to highlight 'at risk' groups and identify the most marginal nutrients in the diet; as such they give a more sensitive indication of likely inadequacy than the use of RNIs. In this study there appeared to be a shortfall in intake for several nutrients, and this was more marked among women. With regard to minerals, $9 \%$ of women ( $5 \%$ of men) had calcium intakes below the LRNI, while $4 \%$ of women (less than $1 \%$ of men) failed to meet the LRNI for iron. With regard to vitamins, $9 \%$ of women had intakes of riboflavin below the LRNI ( $4 \%$ of men), while $5 \%$ of women (less than $1 \%$ of men) had very low intakes of folate. Intakes of vitamin D were extremely low, and few people reached the RNI (there is no official LRNI for vitamin D). The recommended intake ${ }^{1}$ of $10 \mu \mathrm{g}$ day $^{-1}$ is difficult to achieve without the use of supplements.

The percentage of men and women with micronutrient intakes below the LRNI was compared across quartiles of dietary NMES (Table 4). In women, none of the differences between NMES groups were statistically significant. In men, there was a higher prevalence of low folate intakes in Q3 of NMES but no clear trend.

\section{Micromutrient status}

Biochemical status indices investigated in this project included: haemoglobin, serum ferritin and transferrin saturation (for iron status); alkaline phosphatase (indicator of bone health); plasma vitamin C; plasma 25-hydroxy vitamin $\mathrm{D}$; erythrocyte glutathione reductase coefficient (EGRAC) (for riboflavin status); and serum folate and red cell folate (for folate status). Mean values of biochemical indices were compared across NMES groups (Table 5) and the percentage of men and women below conventional thresholds indicative of tissue deficiency were also assessed (Table 6).

\section{Iron status}

The protocol for the present study involved excluding people on medication for nutritional and blood disorders
Table 4 Percentage of men and women with micronutrient intakes below the LRNI according to level of dietary NMES

\begin{tabular}{|c|c|c|c|c|c|c|}
\hline \multirow[b]{2}{*}{$M E N$} & \multicolumn{4}{|c|}{ NMES quartile } & \multirow[b]{2}{*}{ All men } & \multirow[b]{2}{*}{$P$-value } \\
\hline & 1 & 2 & 3 & 4 & & \\
\hline \multicolumn{7}{|c|}{$\%$ of adults below LRNI for: } \\
\hline Calcium & 6 & 3 & 3 & 9 & 5 & NS \\
\hline Iron & $<1$ & 0 & 3 & 0 & $<1$ & NS \\
\hline Riboflavin $\left(\mathrm{B}_{2}\right)$ & 4 & 5 & 4 & 6 & 4 & NS \\
\hline Folate & 0 & 0 & 3 & 0 & $<1$ & 0.03 \\
\hline Vitamin C & 2 & $<1$ & 2 & 2 & 2 & NS \\
\hline \multirow[t]{2}{*}{ Vitamin $D^{*}$} & 94 & 97 & 97 & 96 & 96 & NS \\
\hline & \multicolumn{4}{|c|}{ NMES quartile } & & \\
\hline WOMEN & 1 & 2 & 3 & 4 & All women & $P$-value \\
\hline \multicolumn{7}{|c|}{$\%$ of adults below LRNI for: } \\
\hline Calcium & 14 & 10 & 3 & 7 & 9 & NS \\
\hline Iron & 2 & 5 & 1 & 7 & 4 & NS \\
\hline Riboflavin $\left(\mathrm{B}_{2}\right)$ & 14 & 10 & 3 & 11 & 9 & NS \\
\hline Folate & 6 & 3 & 2 & 6 & 5 & NS \\
\hline Vitamin C & 3 & 3 & 0 & 1 & 2 & NS \\
\hline Vitamin D* & 97 & 98 & 100 & 100 & 99 & NS \\
\hline
\end{tabular}

NS $=$ not significant.

* Percentage below RNI (no LRNI set).

such as anaemia. Therefore the values given below underestimate the true prevalence of low iron status in the population.

Haemoglobin levels were below the deficiency thresholds (130 $\mathrm{g} \mathrm{l}^{-1}$ for men; $120 \mathrm{~g} \mathrm{l}^{-1}$ for women) for $13 \% \mathrm{of}$ men and $11 \%$ of women. However, there was no difference among NMES groups in either mean values or the percentage of adults with low status. Mean ferritin levels were highest in Q1 (for men only), but because these can be distorted by infection, the percentage of adults with low status $\left(<12 \mu \mathrm{g} \mathrm{l}^{-1}\right)$ is a more reliable indicator of low iron stores. Five per cent of men and 10\% of women had low iron stores using this criterion, but the proportion did not vary significantly according to NMES intake. A third index of iron deficiency is provided by the percentage of the iron transport protein that is saturated with iron (transferrin saturation \%). When this drops to $15 \%$, haemoglobin formation is likely to be impaired ${ }^{4}$. The mean \% transferrin saturation was $28 \%$ for men and $24 \%$ for women, with no difference between high and low NMES consumers. More women (17\%) than men (8\%) had values below the threshold but this was unrelated to NMES intakes.

\section{Bone bealth}

Plasma calcium is homeostatically controlled and so is not an indicator of calcium status. High levels of alkaline phosphatase (APT) are indicative of high bone turnover and vitamin D deficiency, although they can also occur in bone cancer and biliary obstruction. Men with high NMES intakes had the highest mean values of APT ( $P$-value for Q4 vs. Q1 = 0.003). The percentage of men with high APT levels was 20\% in Q4, compared with 12\% in Q1, but 
Table 5 Mean values of biochemical status indices, according to level of dietary NMES

\begin{tabular}{|c|c|c|c|c|c|c|c|c|}
\hline \multirow[b]{2}{*}{$M E N$} & & \multicolumn{4}{|c|}{ NMES quartile } & \multirow[b]{2}{*}{ All men } & \multirow{2}{*}{$\begin{array}{l}P \text {-value } \\
\text { (ANOVA, } \\
\text { all groups) }\end{array}$} & \multirow{2}{*}{$\begin{array}{c}P \text {-value } \\
\text { (Q4 vs. Q1) }\end{array}$} \\
\hline & & 1 & 2 & 3 & 4 & & & \\
\hline \multirow[t]{2}{*}{ Haemoglobin $\left(\mathrm{g} \mathrm{I}^{-1}\right)$} & Mean & 14.5 & 14.5 & 14.4 & 14.3 & 14.5 & NS & NS \\
\hline & SE & 0.1 & 0.1 & 0.1 & 0.1 & 0.1 & & \\
\hline \multirow[t]{2}{*}{ Ferritin $\left(\mu \mathrm{g} \mathrm{I}^{-1}\right)$} & Mean & 154 & 106 & 109 & 118 & 122 & 0.011 & 0.021 \\
\hline & SE & 15 & 8 & 9 & 10 & 6 & & \\
\hline \multirow{2}{*}{ Transferrin saturation (\%) } & Mean & 28.9 & 26.6 & 27.7 & 29.1 & 28.1 & NS & \\
\hline & SE & 1.1 & 0.9 & 1.1 & 1.0 & 0.5 & & \\
\hline \multirow[t]{2}{*}{ Alkaline phosphatase (iu I ${ }^{-1}$ ) } & Mean & 81 & 87 & 84 & 94 & 87 & 0.012 & 0.003 \\
\hline & SE & 3 & 4 & 3 & 4 & 2 & & \\
\hline \multirow[t]{2}{*}{ Riboflavin (EGRAC) } & Mean & 1.30 & 1.30 & 1.31 & 1.31 & 1.30 & NS & NS \\
\hline & SE & 0.02 & 0.02 & 0.02 & 0.02 & 0.01 & & \\
\hline \multirow[t]{2}{*}{ Serum folate $\left(\mathrm{nmol} \mathrm{I}{ }^{-1}\right)$} & Mean & 16.1 & 15.1 & 14.3 & 15.1 & 15.2 & NS & NS \\
\hline & SE & 1.0 & 0.9 & 0.9 & 1.0 & 0.5 & & \\
\hline \multirow{2}{*}{ Red cell folate $\left(\mathrm{nmol} \mathrm{I}{ }^{-1}\right)$} & Mean & 533 & 489 & 464 & 462 & 487 & 0.024 & 0.006 \\
\hline & SE & 25 & 24 & 24 & 28 & 13 & & \\
\hline \multirow[t]{2}{*}{ Plasma vitamin $C\left(\mu \mathrm{mol} \mathrm{I}{ }^{-1}\right)$} & Mean & 38.5 & 38.3 & 41.4 & 35.5 & 38.4 & NS & NS \\
\hline & SE & 2.1 & 2.1 & 2.3 & 2.2 & 1.1 & & \\
\hline \multirow[t]{2}{*}{ Plasma vitamin $\mathrm{D}\left(\mathrm{nmol} \mathrm{I}{ }^{-1}\right)$} & Mean & 59.0 & 59.2 & 56.6 & 57.8 & 58.1 & NS & NS \\
\hline & & \multicolumn{4}{|c|}{ NMES quartile } & & $P$-value & \\
\hline \multicolumn{2}{|l|}{ WOMEN } & 1 & 2 & 3 & 4 & All women & all groups) & (Q4 vs. Q1) \\
\hline \multirow[t]{2}{*}{ Haemoglobin $\left(\mathrm{g} \mathrm{I}^{-1}\right)$} & Mean & 13.4 & 13.5 & 13.5 & 13.4 & 13.4 & NS & NS \\
\hline & SE & 0.1 & 0.1 & 0.1 & 0.1 & 0.1 & & \\
\hline \multirow[t]{2}{*}{ Ferritin $\left(\mu \mathrm{g} \mathrm{I}^{-1}\right)$} & Mean & 81.4 & 75.0 & 82.5 & 67.6 & 76.6 & NS & NS \\
\hline & SE & 7.6 & 7.4 & 10.3 & 5.8 & 4.0 & & \\
\hline \multirow[t]{2}{*}{ Transferrin saturation (\%) } & Mean & 25.2 & 22.4 & 26.4 & 22.4 & 24.1 & 0.039 & NS \\
\hline & SE & 1.2 & 0.9 & 1.2 & 0.9 & 0.5 & & \\
\hline \multirow[t]{2}{*}{ Alkaline phosphatase (iu I ${ }^{-1}$ ) } & Mean & 109 & 91 & 103 & 93 & 99 & NS & NS \\
\hline & SE & 15 & 3 & 14 & 4 & 5 & & \\
\hline \multirow[t]{2}{*}{ Riboflavin (EGRAC) } & Mean & 1.31 & 1.27 & 1.28 & 1.29 & 1.29 & NS & NS \\
\hline & SE & 0.02 & 0.01 & 0.01 & 0.01 & 0.01 & & \\
\hline \multirow[t]{2}{*}{ Serum folate $\left(\mathrm{nmol} \mathrm{I}^{-1}\right)$} & Mean & 16.6 & 19.0 & 17.3 & 15.7 & 17.1 & NS (0.053) & NS \\
\hline & SE & 1.1 & 1.1 & 1.1 & 1.1 & 0.6 & & \\
\hline \multirow[t]{2}{*}{ Red cell folate $(\mathrm{nmol} \mathrm{I}-1)$} & Mean & 498 & 567 & 469 & 489 & 506 & NS $(0.060)$ & NS \\
\hline & SE & 29 & 34 & 24 & 33 & 15 & & \\
\hline \multirow[t]{2}{*}{ Plasma vitamin $C\left(\mu \mathrm{mol} \mathrm{I}{ }^{-1}\right)$} & Mean & 42.1 & 48.3 & 51.2 & 45.8 & 46.9 & NS & NS \\
\hline & SE & 2.6 & 2.7 & 2.9 & 2.5 & 1.3 & & \\
\hline \multirow[t]{2}{*}{ Plasma vitamin $\mathrm{D}\left(\mathrm{nmol} \mathrm{I}{ }^{-1}\right)$} & Mean & 50.3 & 50.4 & 53.3 & 47.1 & 50.3 & NS & NS \\
\hline & SE & 2.3 & 2.5 & 2.7 & 2.3 & 1.2 & & \\
\hline
\end{tabular}

ANOVA $=$ analysis of variance; $N S=$ not significant.

this difference was not statistically significant. Among women, there was no trend.

\section{Vitamin D status}

Poor vitamin D status was a major finding of the official survey report, more particularly among the institutional sample ${ }^{4}$. In the present study of free-living subjects, $13 \%$ of women and $6 \%$ of men had plasma levels of vitamin D that were below the normal range. However, there was no evidence of an association with NMES

\section{Vitamin C status}

Plasma vitamin $\mathrm{C}$ concentrations reflect recent intake, but are reduced by smoking. The group of men with the highest NMES intake (Q4) contained slightly more smokers, but this was not significant. Sixteen per cent of men and $14 \%$ of women had low vitamin C status, but there was no significant difference in prevalence (or in mean intakes) across quartiles of NMES.

\section{Riboflavin status}

The high prevalence of poor riboflavin status found in this survey $(38 \%$ of men and women with EGRAC $>1.3$ ) contrasts with the smaller percentage of adults with riboflavin intakes below the LRNI $(<10 \%)$. This paradox has been commented on in a recent review of the NDNS survey $^{15}$ and also noted in other studies ${ }^{16-18}$. In men there was no difference in the prevalence of low riboflavin status among NMES groups. In women the highest prevalence was found among those with intakes at either extreme of NMES in the diet (Q1 and Q4).

\section{Folate status}

Serum folate reflects recent dietary intake. Red cell folate 
Table 6 Percentage of men and women with biochemical status indices in the range associated with tissue deficiency

\begin{tabular}{|c|c|c|c|c|c|c|}
\hline \multirow[b]{2}{*}{ MEN } & \multicolumn{4}{|c|}{ NMES quartile } & \multirow[b]{2}{*}{ All men } & \multirow[b]{2}{*}{ Chi-square $P$-value } \\
\hline & 1 & 2 & 3 & 4 & & \\
\hline \multicolumn{7}{|l|}{$\%$ of adults with low status for: } \\
\hline Haemoglobin $\left(<130 \mathrm{~g} \mathrm{I}^{-1}\right)$ & 12 & 12 & 10 & 17 & 13 & NS \\
\hline Ferritin $\left(<12 \mu \mathrm{g} \mathrm{I}^{-1}\right)$ & 3 & 5 & 7 & 4 & 5 & NS \\
\hline Transferrin saturation $(<15 \%)$ & 5 & 12 & 9 & 6 & 8 & NS \\
\hline Alkaline phosphatase $\left(>110\right.$ iu I $\left.{ }^{-1}\right)$ & 12 & 12 & 14 & 20 & 15 & NS \\
\hline Riboflavin (EGRAC > 1.3) & 37 & 39 & 39 & 35 & 38 & NS \\
\hline Serum folate $\left(<7 \mathrm{nmol} \mathrm{I}^{-1}\right)$ & 13 & 17 & 22 & 24 & 19 & NS (linear $P=0.023$ ) \\
\hline Red cell folate $\left(<230 \mathrm{nmol} \mathrm{I}^{-1}\right)$ & 8 & 9 & 7 & 11 & 9 & NS \\
\hline Vitamin $\mathrm{C}\left(<11 \mu \mathrm{mol} \mathrm{I}^{-1}\right)$ & 16 & 16 & 12 & 21 & 16 & NS \\
\hline \multirow[t]{2}{*}{ Vitamin $\mathrm{D}\left(<25 \mathrm{nmol} \mathrm{I}^{-1}\right)$} & 7 & 7 & 7 & 6 & 6 & NS \\
\hline & \multicolumn{4}{|c|}{ NMES quartile } & & \\
\hline WOMEN & 1 & 2 & 3 & 4 & All women & Chi-square $P$-value \\
\hline \multicolumn{7}{|l|}{$\%$ of adults with low status for: } \\
\hline Haemoglobin $\left(<120 \mathrm{~g} \mathrm{I}^{-1}\right)$ & 13 & 11 & 7 & 12 & 11 & NS \\
\hline Ferritin $\left(<12 \mu \mathrm{g} \mathrm{I}^{-1}\right)$ & 9 & 11 & 11 & 9 & 10 & NS \\
\hline Transferrin saturation $(<15 \%)$ & 14 & 22 & 12 & 19 & 17 & NS \\
\hline Alkaline phosphatase $\left(>110\right.$ iu I $\left.{ }^{-1}\right)$ & 22 & 20 & 20 & 17 & 20 & NS \\
\hline Riboflavin (EGRAC > 1.3) & 47 & 27 & 33 & 44 & 38 & 0.015 \\
\hline Serum folate $\left(<7 \mathrm{nmol} \mathrm{I}^{-1}\right)$ & 15 & 11 & 12 & 18 & 14 & NS \\
\hline Red cell folate $\left(<230 \mathrm{nmol} \mathrm{I}^{-1}\right)$ & 4 & 5 & 5 & 14 & 7 & 0.037 \\
\hline Vitamin $C\left(<11 \mu \mathrm{mol} \mathrm{I}^{-1}\right)$ & 17 & 11 & 14 & 15 & 14 & NS \\
\hline Vitamin $\mathrm{D}\left(<25 \mathrm{nmol} \mathrm{I}^{-1}\right)$ & 14 & 11 & 13 & 13 & 13 & NS \\
\hline
\end{tabular}

NS $=$ not significant

(RCF) is a better measure of longer-term folate status because it reflects body stores at the time of red cell synthesis. Serum folate tended to give higher estimates of the prevalence of poor folate status at cut-offs used ( $7 \mathrm{nmol} \mathrm{l}^{-1}$ for serum folate; $230 \mathrm{nmol} \mathrm{l}^{-1}$ for red cell folate). Men with the highest NMES intakes (Q4) had a significantly lower mean RCF than men in Q1 (Q4 vs. Q1; $P=0.006$ ). The proportion of men with $\mathrm{RCF}<$ $230 \mathrm{nmoll}^{-1}$ was also slightly higher in Q4 than in the other groups, but this failed to reach significance. Mean levels of serum folate did not differ significantly across the NMES groups, although there was an increasing prevalence of low serum folate values as NMES intakes rose ( $P=0.023$ for linear association). Among women, NMES intake was weakly associated with low RCF status ( $4 \%$ in Q1 vs. $14 \%$ in Q4; $P=0.037$ ), although no other differences in folate indices were significant.

\section{Discussion}

Intakes of NMES among the older people in this survey were slightly lower than in comparable surveys of British adults $(13-14 \%)^{19}$. The comment by the COMA Panel on the Nutrition of Elderly People that this age group tends to have above average intakes of sugars ${ }^{2}$ may therefore be more applicable to adults living in institutions than to the older population in general. Since NMES intakes in the institutional sample averaged $18 \%$ of energy ${ }^{4}$, there may be grounds for further investigation of the nutrient dilution issue in this group of vulnerable people.
The results of this study suggest that the association between level of NMES in the diet and micronutrient nutrition is complex. Broad generalisations that NMES dilute the nutritional quality of the diet and compromise micronutrient status may not be justified, but neither is their refutation straightforward. There is a need to define and quantify the issues more accurately: for which nutrients are intake and/or status likely to be sub-optimal, for which groups of the population, and at what level do sugars influence dietary quality?

The public health significance of nutrient dilution will depend on the level of that nutrient in the average diet and the prevalence of deficiency in the community. Where dietary adequacy is normally assured, for example in the case of thiamin and niacin, the question of nutrient dilution by sugars becomes academic. However, in the case of more marginal nutrients, such as riboflavin or folate, a small effect that compromises nutrient intake or status assumes greater importance. One shortcoming of the present study relates to the selection of nutrients studied. While these are major nutrients of nutritional significance and indicators of a balanced diet, minor nutrients have not been included in this paper. Published work has suggested that magnesium, zinc and vitamin $\mathrm{B}_{6}$ intakes may be marginal in this population ${ }^{15,20}$ and the correlates of this deserve further investigation.

This study has attempted to identify and quantify relationships between NMES intake and both micronutrient intake and status. For many nutrients, the trend of intakes with level of NMES in the diet appears not to be 
linear, but bell-shaped, with nutrient intakes optimal at average levels of intake (8-15\% of energy from NMES). In women particularly, very low sugar diets $(<8 \%$ of energy from NMES) were associated with low intakes of some minerals and vitamins (calcium, iron, riboflavin, folate and vitamin C). This is partly attributable to low energy intakes, which are a better indicator of micronutrient adequacy than dietary sugars concentration ${ }^{3}$. Thus in univariate regression analyses, energy intake explained between $20 \%$ and $40 \%$ of the variance in intake of iron, calcium, riboflavin and folate, while percentage energy from NMES explained, at most, 4\%. Exclusion of underreporters, who were over-represented in Q1, ameliorated the low energy and nutrient intakes among low NMES consumers (data not shown). However, it did not abolish the bell-shaped associations entirely, nor did it alter the relationships observed between micronutrient intakes and NMES in Q2 to Q4.

In evaluating the significance for public health, the percentage of individuals with nutrient intakes below the LRNI may be more informative than the mean intake of each group. Overall, small numbers of men $(<5 \%)$ and slightly more women $(<9 \%)$ were estimated to have intakes of one or more micronutrients that fell below the LRNI, and exclusion of low energy reporters reduced this further, to $1 \%$ of men and to $6 \%$ of women (data not shown). There was no evidence that the prevalence of inadequacy (defined as intakes below the LRNI) was increased among elderly adults with diets high in NMES.

The biochemical measurements for the sample as a whole suggested that the status of several nutrients might be sub-optimal, to a greater extent than expected from the dietary assessments. For vitamin C, only $2 \%$ of men and women were judged to have inadequate intakes, yet $16 \%$ of men and $14 \%$ of women had values of plasma ascorbate below the lower normal range. The true prevalence of iron deficiency and anaemia is underestimated in this analysis because respondents on medication for anaemia were excluded at the outset. For riboflavin, less than $10 \%$ of men and women had intakes below the LRNI, whereas 38\% were judged deficient on the status measurement (EGRAC). This paradox has been noted before in this same population ${ }^{15}$ and in other surveys of older people $\mathrm{e}^{16,17}$. It was also a finding in the recent survey of school children ${ }^{18}$, where the status results were attributed to the sensitive assay used. It is possible that the Dietary Reference Values for riboflavin may be set too low, but the threshold value for EGRAC may also be too sensitive, since moderately raised values are not associated with known functional abnormality ${ }^{18}$.

The results for folate deserve special mention because there is now evidence that sub-optimal folate status is a risk factor for cardiovascular disease $(\mathrm{CVD})^{21}$, probably through its association with higher levels of plasma homocysteine ${ }^{22,23}$. Moreover, interventions have recently shown that homocysteine can be lowered by folate supplementation $^{24,25}$. However, the small inverse association of NMES with folate status found in the present study is probably spurious. Firstly, it was not robust, losing statistical significance when under-reporters were excluded. Neither was there a plausible mechanism, since folate intakes did not differ significantly across quartiles of NMES. Instead, the association probably reflects the confounding impact of smoking. Regression analyses, conducted to test this, showed that the number of cigarettes smoked was significantly related to red cell folate levels in both men and women, whereas neither age nor NMES intake was a significant predictor of poor folate status. Smoking has also been associated with poorer folate status in a more detailed analysis of this dataset $^{26}$ and in other populations ${ }^{27,28}$.

Even if it is not related to dietary NMES concentration, sub-optimal folate status may be a matter of concern for this age group generally. The appropriate cut-off level for serum folate is a matter of continuing debate ${ }^{29,30}$, but in this population more than 16\% (19\% of men and 14\% of women) had serum folate levels indicative of early negative folate balance $\left(<7 \mathrm{nmol} \mathrm{l}^{-1}\right)^{4}$. This compares with a prevalence of low status of $6-8 \%$ among Dutch men and women aged 50-79 years, using the same threshold ${ }^{31}$.

All prevalence estimates rest on the cut-offs chosen, and measure different parameters; therefore they cannot be expected to produce identical values for intakes and status. Nevertheless, the discrepancies between estimates of sub-optimal intake and sub-optimal status deserve more attention. There is a need to identify functional markers for low status and understand their relationship to current status indices. More data are also required on how status measurements are influenced by nutrient intake and physiological/medical factors. Considerable progress has been made in this area ${ }^{32-34}$ but many mechanisms remain poorly understood.

The results of this analysis suggest that a small proportion of the general population of normal, freeliving people over the age of 65 years may be at risk of sub-optimal nutrient status. Some diets, if representative of longer-term intake, may be inadequate if consumed by those individuals with higher than average requirements.

In the present study, there was no evidence that NMES intakes in the broad normal range for free-living older people (8-15\% of energy) were detrimental to micronutrient intake or status. Diets outside this range $(<8 \%$ or $>15 \%$ ) tended to be marginally lower in some nutrients, but the impact of a diet high in NMES would appear to be of minor significance compared with that of total energy intake.

\section{Acknowledgements}

The National Diet and Nutrition Survey of people aged 65 years or over was funded jointly by the Ministry of Agriculture, Fisheries and Food (MAFF) and the 
Department of Health, and was conducted by the Social and Community Planning Research (SCPR) in conjunction with the Medical Research Council's Human Nutrition Research, the University of Newcastle, University College London and the University of Birmingham. The dataset was supplied by the UK Data Archive. Those responsible for the original collection of the data bear no responsibility for its further analysis or interpretation. The author (S Gibson) received support from the Sugar Bureau.

\section{References}

1 Department of Health. Dietary Reference Values for Food Energy and Nutrients for the United Kingdom. London: HMSO, 1991.

2 Department of Health. The Nutrition of Elderly People. London: HMSO, 1992.

3 Department of Health and Social Security. Dietary Sugars and Human Disease. Committee on Medical Aspects of Food Policy. Report on Health and Social Subjects 37. London: HMSO, 1989.

4 Finch S, Doyle W, Lowe C, Bates C, Prentice A, Smithers G, Clarke P. National Diet and Nutrition Survey: People aged 65 years and over. Vol. 1. Report of the Diet and Nutrition Survey. London: The Stationery Office, 1998.

5 UDSA Center for Nutrition Policy and Promotion. Is intake of added sugars associated with diet quality? Nutrition Insights 2000; 21: 1-2.

6 Rugg-Gunn AJ, Hackett AF, Jenkins GN, Appleton DR. Empty calories? Nutrient intake in relation to sugar intake in English adolescents. J. Hum. Nutr. Diet. 1991; 4: 101-11.

7 Nelson M. Workshop on Nutrition and the Schoolchild. Food, vitamins and IQ. Proc. Nutr. Soc. 1991; 50: 29-35.

8 Gibson S. Consumption and sources of sugars in the diets of British schoolchildren: are high-sugar diets nutritionally inferior? J. Hum. Nutr. Diet. 1993; 6: 355-71.

9 Naismith D, Nelson M, Burley V, Gatenby S. Does a high sugar diet promote overweight in children and lead to nutrient deficiencies? J. Hum. Nutr. Diet. 1995; 8: 249-54.

10 Gibson SA. Non-milk extrinsic sugars in the diets of preschool children: association with intakes of micronutrients, energy, fat and NSP. Br. J. Nutr. 1997; 78: 367-78.

11 Gibson S. Do diets high in sugars compromise micronutrient intakes? J. Hum. Nutr. Diet. 1997; 10: 125-33.

12 Bolton-Smith C. Intake of sugars in relation to fatness and micronutrient adequacy. Int. J. Obes. Relat. Metab. Disord. 1996; 20(Suppl. 2): S31-3.

13 Gibney M, Sigman-Grant M, Stanton JL Jr, Keast DR. Consumption of sugars. Am. J. Clin. Nutr. 1995; 62: 178S93S.

14 Goldberg GR, Black AE, Jebb SA, Cole TJ, Murgatroyd PR, Coward WA, Prentice AM. Critical evaluation of energy intake data using fundamental principles of energy physiology: 1. Derivation of cut-off limits to identify under-recording. Eur. J. Clin. Nutr. 1991; 45: 569-81.

15 Bates CJ, Prentice A, Cole TJ, van der Pols JC, Doyle W, Finch S, Smithers G, Clarke PC. Micronutrients: highlights and research challenges from the 1994-5 National Diet and Nutrition Survey of people aged 65 years and over. $\mathrm{Br} . J$. Nutr. 1999; 82: 7-15.

16 Bailey AL, Maisey S, Southon S, Wright AJ, Finglas PM, Fulcher RA. Relationships between micronutrient intake and biochemical indicators of nutrient adequacy in a freeliving elderly UK population. Br. J. Nutr. 1997; 77: 225-42.

17 Madigan SM, Tracey F, McNulty H, Eaton-Evans J, Coulter J, McCartney H, Strain JJ. Riboflavin and vitamin B-6 intakes and status and biochemical response to riboflavin supplementation in free-living elderly people. Am. J. Clin. Nutr. 1998; 68: 389-95.

18 Gregory J, Lowe S. National Diet and Nutrition Survey: Young People aged 4 to 18 years. Vol. 1. Report of the Diet and Nutrition Survey. London: The Stationery Office, 2000.

19 Gregory J, Foster K, Tyler H, Wiseman M. The Dietary and Nutritional Survey of British Adults. London: HMSO, 1990.

20 Bates CJ, Pentieva KD, Prentice A, Mansoor MA, Finch S. Plasma pyridoxal phosphate and pyridoxic acid and their relationship to plasma homocysteine in a representative sample of British men and women aged 65 years and over. Br. J. Nutr. 1999; 81: 191-201.

21 Ford ES, Byers TE, Giles WH. Serum folate and chronic disease risk: findings from a cohort of United States adults. Int. J. Epidemiol. 1998; 27: 592-8.

22 Selhub J, Jacques PF, Wilson PW, Rush D, Rosenberg IH. Vitamin status and intake as primary determinants of homocysteinemia in an elderly population. JAMA 1993; 270: 2693-8.

23 Koehler KM, Pareo-Tubbeh SL, Romero LJ, Baumgartner RN, Garry PJ. Folate nutrition and older adults: challenges and opportunities. J. Am. Diet. Assoc. 1997; 97: 167-73.

24 Brouwer IAM, van Dusseldorp M, Thomas CM, Duran M, Hautvast JG, Eskes TK, Steegers-Theunissen RP. Low-dose folic acid supplementation decreases plasma homocysteine concentrations: a randomized trial. Am. J. Clin. Nutr. 1999; 69: 99-104

25 Jacques PF, Selhub J, Bostom AG, Wilson PW, Rosenberg $\mathrm{IH}$. The effect of folic acid fortification on plasma folate and total homocysteine concentrations. N. Engl. J. Med. 1999; 340(19): 1449-54.

26 Walmsley CM, Bates CJ, Prentice A, Cole TJ. Relationship between cigarette smoking and nutrient intakes and blood status indices of older people living in the UK: further analysis of data from the National Diet and Nutrition Survey of people aged 65 years and over, 1994/95. Public Health Nutr. 1999; 2: 199-208.

27 Ortega RM, Lopez-Sobaler AM, Gonzalez-Gross MM, et al. Influence of smoking on folate intake and blood folate concentrations in a group of elderly Spanish men. J. Am. Coll. Nutr. 1994; 13: 68-72.

28 Christensen B, Landaas S, Stensvold I, Djurovic S, Retterstol L, Ringstad J, Berg K, Thelle DS. Whole blood folate, homocysteine in serum, and risk of first acute myocardial infarction. Atherosclerosis 1999; 147: 317-26.

29 Jacob RA, Wu MM, Henning SM, Swendseid ME. Homocysteine increases as folate decreases in plasma of healthy men during short-term dietary folate and methyl group restriction. J. Nutr. 1994; 124: 1072-80.

30 Lewis CA, Pancharuniti N, Sauberlich HE. Plasma folate adequacy as determined by homocysteine level. Ann. N.Y. Acad. Sci. 1992; 669: 360-2.

31 Brussaard JH, Lowik MR, van den Berg H, Brants HA, Goldbohm RA. Folate intake and status among adults in the Netherlands. Eur. J. Clin. Nutr. 1997; 51(Suppl. 3): S4650.

32 Doyle W, Crawley H, Robert H, Bates CJ. Iron deficiency in older people: interactions between food and nutrient intakes with biochemical measures of iron; further analysis of the National Diet and Nutrition Survey of people aged 65 years and over. Eur. J. Clin. Nutr. 1999; 53: 552-9.

33 Walmsley CM, et al. Relationship between alcohol and nutrient intakes and blood status indices of older people living in the UK: further analysis of data from the National Diet and Nutrition Survey of people aged 65 years and over, 1994/5. Public Health Nutr. 1998; 1(3): 157-67.

34 Bates CJ, Walmsley CM, Prentice A, Finch S. Use of medicines by older people in a large British national survey, and their relation to vitamin status indices. Public Health Nutr. 1999; 2(1): 15-22. 